\section{SOI: $1.1 /$ TAS DOI: $10.15863 / \mathrm{TAS}$ International Scientific Journal Theoretical \& Applied Science}

\author{
p-ISSN: 2308-4944 (print) e-ISSN: 2409-0085 (online) \\ Year: $2015 \quad$ Issue: 04 Volume: 24
}

Published: $30.04 .2015 \quad$ http://T-Science.org

SECTION 31. Economic research, finance, innovation, risk management.
Santay Azizbekovna Tleubayeva candidate of economics, trainee Department of Accounting, analysis and audit Lomonosov Moscow State University, Russia ms.santay@mail.ru

Sagynkul Zhuanyshovna Pralieva candidate of economics, docent of the Department "Finance"

Turan University, Kazakhstan maika.kz@mail.ru

Tatyana V. Fursova candidate of economics, docent of the Department "Finance"

Turan University, Kazakhstan

Aigul Makulbekkyzy Bakirbekova candidate of economics, docent of the Department "Management" L.N.Gumilyov Eurasian National University, Kazakhstan

Viktoriya Dmitrievna Zabolotnikova

PhD student, "Economy", 2nd year

Turan University, Kazakhstan

\title{
INVESTING ACTIVITIES OF THE REPUBLIC OF KAZAKHSTAN AND FACTORS SHAPES
}

\begin{abstract}
Describes the main factors that contribute to high-quality measurement of risks and methods of investment activity in the global crisis. It is shown how structural imbalances in the economy were the main obstacle improving investment activity. The author's approach to the explanation of the reasons for the failure of the investment activity in the manufacturing sector of the economy and the development of new strategies for improving investment activity. The necessity of conducting a comprehensive study of the existing system of protection of the interests of "unskilled", retail, investors in the Republic of Kazakhstan.

Key words: World Bank, investment climate, methods of crisis management, retail investors, investment, competitiveness, global crisis, strategy, public policy, financial sector.

Language: Russian

Citation: Tleubayeva SA, Pralieva SZ, Fursova TV, Bakirbekova AM, Zabolotnikova VD (2015) INVESTING ACTIVITIES OF THE REPUBLIC OF KAZAKHSTAN AND FACTORS SHAPES. ISJ Theoretical \& Applied Science 04 (24): 113-119.

Soi: http://s-o-i.org/1.1/TAS*04(24)18 Doi: rossef http://dx.doi.org/10.15863/TAS.2015.04.24.18

\section{ИНВЕСТИЦИОННАЯ ДЕЯТЕЛЬНОСТЬ РЕСПУБЛИКИ КАЗАХСТАН И ФАКТОРЫ ЕЕ ФОРМИРУЮЩИЕ}

Аннотация: Описаны основные факторы, обуславливающие качественное изменение рисков и методов инвестиционной деятельности в условиях глобального кризиса. Показано как структурные диспропорчии в экономике стали главным препятствием совершенствования инвестиционной деятельности. Представлен авторские подходы к объяснению причин фактического провала инвестиционной деятельности в обрабатывающих отраслях экономики и разработке новой стратегии совершенствования инвестициионой деятельности. Обоснована необходимость проведения комплексного исследования существующей системы защиты интересов «неквалифицированньх» (розничных) инвесторов в Республике Казахстан.

Ключевые слова: Всемирный Банк, инвестиционный климат, методы антикризисного регулирования, розничные инвесторы, инвестиционная деятельность, конкурентоспособность, глобальный кризис, стратегия, государственная политика, финансовый сектор.

Глобальный кризис мировой экономики создал качественно новые условия инвестиционной деятельности - в том числе, и для Казахстана. Как видно из доклада
Всемирного Банка (ВБ), опубликованного в начале 2014 года, общее снижение эффективности методов управления рисками в условиях кризиса повлекло за собой 
значительные перемены в поведении розничных инвесторов и изменение стратегий большинства инвестиционных институтов [1].

На фоне этих изменений в глобальном инвестиционном климате стали особенно заметными:

1. Отсутствие в экономической науке единства взглядов на природу экономических кризисов и методы антикризисного регулирования.

В настоящее время, нет не только экономических теорий, позволяющих на практике проводить научно обоснованную экономическую политику, но и международного опыта эффективного антикризисного регулирования экономики. В XX веке финансовые и экономические кризисы стали явлением привычным и даже обыденным. Только в 1975-1997гг. МВФ зарегистрировал более 150 валютных и 54 долговых и банковских кризисов в более чем 50 странах [2]. Кажется, и времени, и побудительных причин для их разработки было вполне достаточно. Тем не менее, «экономическая наука пока не содержит в себе полностью законченных теорий, которые объяснили бы абсолютный и крайне простой эмпирический факт нестабильности рыночного способа производства» [3]. Особенно ярко в условиях кризиса проявилась «неадекватность неоклассической парадигмы реальным процессам экономического развития и иллюзорность лежащих в её основе аксиом - начиная от обладающего абсолютным знанием homo economicus и заканчивая совершенной конкуренцией» [4].

2. Качественно новый уровень глобализации мировой экономики, который повлёк за собой возникновение качественно новых инвестиционных рисков [5].

Анализ структур капитала и управления 43000 крупных международных компаний, работающих в реальной экономике, проведённый швейцарскими математиками, привёл их к выводу: большинство финансовых цепочек идут в направлении группы из 147 компаний, активы которых пересекаются друг с другом, фактически являясь общей собственностью. Фактически сегодня это одна гигантская корпорация - куда более влиятельная, чем подавляющее большинство национальных правительств [6]. Причем речь не об американской (и вообще не о западной) a, о качественно новой «корпоратократии» [7], которой глубоко чужды национальные интересы, для которой «одержимость национальной конкурентоспособностью является одновременно ошибочной и опасной» [8, с.240].

Финансово-политическая олигархия стран Запада, интересы которой ранее на протяжении многих десятилетий воплощались в геополитике США, к настоящему времени полностью интегрировалась с лидерами китайских диаспор и правящей верхушкой многих нефтегазодобывающих стран арабского мира. Несмотря на различия в политике, культуре, ценностях, они превратились в единую глубоко интегрированную систему. Об этом, как об «упущенных возможностях», с тревогой пишет один из главных идеологов и архитекторов глобализации З.Бжезинский в своей последней книге: «Подходит к концу 500-летняя эпоха мирового доминирования атлантических морских держав и возникает качественно иной мировой порядок - многополярный мир, в котором США больше не сможет, как это было раньше, диктовать свою волю, не можем быть устрашающим глобальным игроком, который регулирует все международные дела в мире» [9, c.26].

3. Непоследовательность, отсутствие стратегического подхода, и, в конечном счёте, крайне низкая эффективность антикризисного регулирования национальных экономик.

Практически во всех странах мира возник «новый политический класс, который нечувствителен к растущему социальному неравенству и который думает только о собственном обогащении» [9, с.12]. Для него «краткосрочные задачи политического выживания оказываются гораздо важнее, чем задачи развития страны; налицо кризис государств, весело и легко практиковавших покупку голосов избирателей за счет взятых в долг денежных средств - задолженности, которую будут выплачивать следующие поколения» [10]. Мир переживает период огромных изменений и масштабного урегулирования, когда все государства стоят перед лицом небывалых возможностей развития и серьезных вызовов. Но планирует и воплощает в жизнь антикризисное регулирование национальных экономик представители «элиты глобального проекта», которой глубоко чужды интересы «каких-то» государств. Именно поэтому правительства подавляющего большинства стран мира не умеют (a, скорее, не хотят и не могут) найти адекватный ответ на эти вызовы.

4. Углубление поляризации общества: на глобальном уровне - между богатыми и бедными странами; на национальном уровне - между кредиторами и должниками. Рост диспропорций в экономике - прежде всего, между финансовым сектором и реальной экономикой.

По словам Н.А.Назарбаева, «в вековой борьбе за политическую демократию человечество проглядело факт создания мировой тоталитарной валютно-финансовой системы, абсолютно лишенной минимальных признаков 
демократии» [11]. Сегодня «и государства, и индивиды пытаются справиться с долгами, уровень которых превышает всякую разумную возможность когда-либо их выплатить: обслуживание долга поглощает большую часть экономического излишка; корпоративные прибыли, ренту за недвижимое имущество, личный доход выше базовых потребностей и даже государственные доходы выше минимально необходимого уровня социальных расходов» [12].

Однако, несмотря на неизбежное влияние всех этих факторов, которые стали причиной качественного изменения подходов к инвестированию во всём мире, за последние пять лет в экономику Казахстана было вложено свыше $\$ 137$ млрд. (в то время как расходы государства на антикризисные меры составили немногим более $\$ 14$ млрд.). И в 2013 году, и в 2014 году в рейтинге ВБ «Doing business» Казахстан занимал 47-е место [13]. По данным опроса, проведенного в 2014г. компанией «Эрнст энд Янг», большинство профессиональных инвесторов, вложивших средства в казахстанские предприятия, «в значительной степени удовлетворены своими инвестиционными решениями» [14, с.13].

При этом, конечно же, нельзя забывать, что львиная доля иностранных инвестиций пошла в сырьевой сектор. Экономика Казахстана базируется на опережающих темпах роста экспорта над импортом; причём рост внешнеторгового оборота обеспечивается у нас, с одной стороны, за счет экспорта углеводородов и других сырьевых товаров, с другой - импортом практически всех товаров, необходимых для обеспечения населения страны [15].

В то же время доля обрабатывающей промышленности в ВВП остается низкой. Численность работников машиностроительной отрасли за годы независимости сократилась с 350 тыс. до 17 тыс. человек. Доля продукции машиностроения в объеме всего промышленного производства - с 15\% до 3,5\%. Казахстанские промышленные предприятия характеризуются крайне низким уровнем производительности труда - в три-четыре раза ниже показателей развитых стран; износ средств производства достигает 70\% [16].

Серьёзные диспропорции наблюдаются не только в отраслевой структуре инвестиций, не только между сырьевым и обрабатывающим секторами экономики Казахстана, но и между крупным, средним и малым бизнесом:

1. Если в развитых странах Запада основная доля занятых в малом и среднем бизнесе, как правило, приходится на промышленность, строительство и сферу услуг, то в Казахстане эти отрасли заняты предприятиями крупного бизнеса; хозяйствующие субъекты малого бизнеса представлены в основном организациями сферы услуг, торговли и сельскохозяйственного производства. По данным опросов, примерно половина казахстанских предпринимателей в казахстанском малом и среднем бизнесе (МСБ) балансируют на грани выживания [17]; вынужденно пришли в малый бизнес более $40 \%$ [18]; более двух третей охотно поменяли бы предпринимательскую деятельность на «достойно оплачиваемую наемную работу» [19].

В целом, по данным Агентства РК по статистике, доля населения, занятого в МСБ, составляет около 25\% трудоспособного населения Казахстана [13] (в то время как, например, в странах Западной Европы этот показатель составляет от 50 до $80 \%$ [20]). Многие представители малого бизнеса в Казахстане относятся органами статистики к категории «самозанятых» - их около 40\% [13], причем на юге страны это основная часть, большинство трудоспособного населения [21]. Они не платят налоги и пенсионные отчисления, их деятельность учитывается органами статистики «оценочно» и относится к «теневой экономике», т.е. на самом деле в казахстанском МСБ занято куда больше, чем $25 \%$ трудоспособного населения, но государство почему-то не может сделать их полноправными участниками экономической деятельности.

Еще в 2014 году Президентом РК Н.А.Назарбаевым была поставлена задача по доведению вклада среднего и малого бизнеса в общий объем ВВП республики к 2014 году до $40 \%$. Однако до настоящего времени эта задача так и не была выполнена. В 2014 году Глава государства снова поставил эту же задачу теперь уже к 2020 году [22]. Его настойчивость в постановке этой задачи обусловлена тем, что, как показывает опыт многих стран, именно предприятия МСБ способны наиболее быстро реагировать на изменения конкурентной среды. И это весомый и стабильный источник налогов: в некоторых регионах и городах мира доля налогов предприятий МСБ доходит до $80 \%$ от их общего объема. Залогом стабильности этих налоговых поступлений является непрерывный процесс самообновления МСБ; на место «неудачников» постоянно приходят новые предприниматели, работает механизм естественного отбора наиболее востребованных и конкурентоспособных предприятий (так, феномен экономического роста Китая основывается, прежде всего, высокими темпами обновления предпринимательской среды, в КНР около 12 миллионов предприятий, из которых ежегодно примерно 1 миллион закрывается и 1 миллион создаётся вновь, доля владельцев предприятий, существующих не более 3,5 лет самая высокая среди всех стран мира - 24\% [23]). 
2. Доля крупного бизнеса в структуре ВВП Казахстана, напротив, стабильно высока; причём наиболее весомая часть таких предприятий принадлежит нерезидентам. Подавляющее большинство крупнейших компаний горнодобывающей промышленности и металлургии, создающих в совокупности более $22 \%$ ВВП, являются или подразделениями транснациональных корпораций, или находятся в долгосрочной концессии у нерезидентов, или контрольный пакет акций принадлежит гражданам зарубежных государств. И именно эти крупные компании привлекают иностранные инвестиции. Об этом, в частности, свидетельствуют размеры и динамика роста валового внешнего долга казахстанских корпораций (без банков). Для Казахстана характерна «локализация центров принятия экономических решений за пределами страны» [24].

Остается значительной и доля государственных предприятий в экономике Казахстана, которые, по утверждению одного из разработчиков программы «Производительность2020», президента Казахстанского института развития индустрии М.З. Кажыкен «как правило, малоэффективны и низкорентабельны» [25].

3. Большинство казахстанских средних компаний, имеющих потенциал роста, не обладают доступом на публичные рынки капитала, испытывают серьезные трудности в финансировании. По данным Казахстанской фондовой биржи (KASE), число компаний, соответствующих листинговым требованиям, не превышает 15-20\% от всех средних и крупных компаний; в 2012 году листинговых компаний было 144, а на начало мая 2014 года их было 108 (всего с нелистинговыми - 116 компаний); на лондонской бирже котируется в общей сложности 41 компания [26]. Акции компаний, которые находятся в листинге «В» Казахстанской фондовой биржи (KASE), считаются неликвидными. Главным образом, из-за непрозрачности бизнеса, ни один внешний инвестор не будет покупать непредсказуемость (показательно, что за первое полугодие 2014 года объем инвестиций казахстанских предприятий в основной капитал составил более 2 триллионов тенге, на 3,1\% больше, чем за этот же период прошлого года; однако при этом казахстанские предприятия существенно увеличили долю собственных инвестиций в основной капитал (с $46 \%$ до 56\%), а вот внешние инвестиции, напротив, сократились) [13].

Диспропорции между сырьевым и обрабатывающим секторами экономики, и между крупным, средним и малым бизнесом, «сложная, но открывающая возможности деловой среды» [14, с.13] сделали весьма проблематичной совершенствование инвестиционной деятельности в Казахстане. За годы независимости было разработано и профинансировано, в общей сложности, около ста различных государственных инвестиционных программ. Достаточно вспомнить: «Стратегию индустриально-инновационного развития Республики Казахстан на 2003-2015 годы», «Формирование и развитие кластеров в условиях индустриально-инновационного развития Республики Казахстан», «30 корпоративных лидеров Казахстана».... Только «Государственной программой форсированного индустриально-инновационного развития Казахстана на 2010-2014 годы» (ГПФИИР) было «прекращено финансирование 52 принятых ранее государственных программ» [27]. Инвестиционные проекты, реализуемые в рамках приоритетов ГПФИИР, были объединены в так называемой «Карте индустриализации» [28]. В ее рамках в 2014г. в эксплуатацию были введены 227 объектов, в которые было инвестировано 914 млрд. тенге (\$6,2 млрд.). И, в свою очередь, ГПФИИР также получила негативную оценку. В частности, потому, что из 31 проекта, составляющих 90\% всех инвестиций по «Карте индустриализации» только пять были связаны с производством готовой продукции. Вклад завершенных инвестиционных проектов «Карты индустриализации» в прирост ВВП, например, в 2013г. не превысил 0,1 процентных пункта, доля их добавленных стоимостей в объеме ВВП едва достигла 0,004. Получается, что для достижения основной цели программы - увеличения реального ВВП на 50\% от уровня 2014г. - надо было бы реализовать более 6000 аналогичных инвестиционных проектов на общую сумму 35-40 трлн. тенге (или \$250 млрд.) [29].

По мнению, высказанному М.З.Кажыкен, главная причина фактического провала инвестиционной деятельности в обрабатывающих отраслях экономики состояла в том, что ГПФИИР, «как и все предшествующие программы, разрабатывалась без научно обоснованной методики, без концептуального видения перспектив развития отраслей как подсистемы глобальной производственной системы» [24].

Соглашаясь в целом с такой оценкой, мы считаем, что причины провала инвестиционной деятельности, как и проблемы казахстанской промышленной политики, несколько иные. Инвестиционная и промышленная политика государства отнюдь не являются результатом согласованных «совместных усилий ученых, практиков, государственных управленцев и бизнес-сообщества» [25]. По определению, потому что это политика - политический 
феномен. Ученые-экономисты только предлагают различные сценарии и программы, разрабатывают идеологическое обоснование принимаемых политических решений. Бизнессообщество голосует за или против проводимой политики ростом или падением инвестиционной активности. Предназначение любой политики - в том числе, экономической, инвестиционной регулирование отношений между отдельными группами национальной элиты, т.е. поддержание баланса интересов:

a) национального олигархического бизнеса, который извлекает сверхприбыли за счёт своего монопольного положения, природной и административной ренты;

б) национальной политической элиты, которая не заинтересована в том, чтобы брать на себя ответственность за реализацию проектов модернизации экономики;

в) международной политико-финансовой «элиты глобального проекта».

Поэтому выбор стратегии, приоритетов и методов инвестиционной деятельности - это не «наука», а «искусство достижения возможного», компромисс, возникающий в результате многофакторной оптимизации разнонаправленных интересов и усилий различных групп политической и финансовой элиты. Ключевая проблема - как нейтрализовать или по крайней мере, ослабить в обществе и государственном аппарате влияние «элиты глобального проекта» и её сторонников.

За последние годы в Казахстане был принят целый ряд мер по совершенствованию инвестиционной деятельности, таких как:

- Концепция развития финансового сектора Республики Казахстан [30] и Закон РК «О внесении изменений и дополнений в некоторые законодательные акты Республики Казахстан по вопросам регулирования банковской деятельности и финансовых организаций в части минимизации рисков» [31];

- Программа «Производительность труда 2020», в рамках которой был проведен технический аудит 200 промышленных предприятий и выделены гранты на разработку бизнес-планов модернизации и технического перевооружения [32];

- Национальный план по привлечению инвестиций, предусматривающий значительные процедурные послабления, создание условий для инвесторов, в том числе в регионах, поддержку и сопровождение инвесторов на всех уровнях [33];

- Программа по развитию государственночастного партнерства (ГЧП), в рамках которой разработан комплекс мер государственной поддержки ГЧП в Казахстане и проект Закона «О внесении изменений и дополнений в некоторые законодательные акты Республики Казахстан по внедрению новых форм государственно-частного партнерства и расширению сфер их применения». В казахстанской практике появятся такие контракты, как Build-Operate-Transfer, BuildOperate-Lease-Transfer, Operations\&Maintenance, Management Contract, Design-Build-FinanceOperate и ряд других общепринятых в мировой практике форм, которые должны обеспечить распределение рисков при инвестировании в капиталоемкие объекты [34];

- Программа «Народное IPO», которая позволит многим казахстанцам стать инвесторами крупнейших национальных компаний. Предприятия-участники «Народного IPO» - входят в группу АО «Фонд национального благосостояния «Самрук-Казына». Организаторы программы учли международный опыт проведения таких мероприятий. Граждане РК имеют приоритетное право на покупку акций; во вторую очередь, ценные бумаги смогут приобрести накопительные пенсионные фонды страны. Чтобы избежать концентрации бумаг в руках небольшой группы лиц, программа предполагает ограничения на максимальное количество приобретаемых акций в «одни руки», а также использование сети АО «Казпочта» для максимального охвата населения. Программой предусмотрено выставить на IPO 10-15 процентные пакеты акций. В 2014 году в первичном публичном размещении акций будет участвовать компания «КазТрансОйл», «Казахстан темир жолы», «Казтемиртранс»; в 2015 году - компании KEGOC, «Эйр Астана», «КазТрансГаз», «Самрук-Энерго», «НМСК «Казтрансморфлот», в 2014 году - «Казахстан темир жолы», «Казтемиртранс», «Казатомпром», «КазМунайГаз» [35].

Исходя из нового видения приоритетов антикризисной экономической политики, сформулированного Президентом РК Н.А.Назарбаевым, в сентябре 2014 года [36], мы полагаем, что дальнейшее совершенствование инвестиционной деятельности предполагает не только и не столько дальнейшее совершенствование инвестиционного климата, направленное на привлечения прямых иностранных инвестиций. В первую очередь, необходимо направить максимум усилий на развитие инвестиционной и предпринимательской активности населения Казахстана, идеи которого положены в основу «Программы по развитию ГЧП» и «Народного IPO».

Мы не будем рассматривать здесь проблемы активизации предпринимательской активности населения - это целый комплекс вопросов, требующий отдельного исследования. Говоря о развитии инвестиционной активности населения, отметим, что на частных вкладах в банках сейчас 
почти три триллиона (2974 млрд.) тенге. Пенсионных - тоже примерно три триллиона (2806 млрд.) тенге. Итого - по состоянию на май 2014г. около \$40 млрд.

Для Казахстана это громадный инвестиционный потенциал, который, заметим, по размеру вполне сопоставим с объемом иностранных инвестиций, привлечённых в экономику Казахстана за последние годы. И особенно значимый в силу того, что население Казахстана - это такой инвестор, которому, в отличие от международной финансовополитической элиты, отнюдь не безразличны национальные интересы.

Для инвестиционной активности населения нам представляется необходимым, в рамках мероприятий по совершенствованию инвестиционной деятельности в Республике Казахстан, проведение комплексного исследования существующей системы защиты интересов «неквалифицированных» (розничных) инвесторов и сформулировать рекомендации по ее совершенствованию.
Основное содержание и планируемые результаты этого исследования, по нашему мнению, могут включать:

1) критический обзор научных трудов по вопросам финансового менеджмента и защиты интересов инвесторов, анализ особенностей правового регулирования защиты интересов казахстанских инвесторов в целях разработки анкет опросов и сценариев интервью;

$2)$ опрос
(розничных) инвестиционных компаний;

3) интервью с «квалифицированными» инвесторами-представителями инвестиционных компаний;

4) изучение деятельности служб внутреннего контроля казахстанских инвестиционных компаний;

5) анализ потенциальных возможностей саморегулируемых организаций по защите интересов казахстанских инвесторов;

6) анализ стереотипов инвестиционного поведения и инвестиционной культуры населения Казахстана.

\section{References:}

1. (2015) Sayt Vsemirnogo Banka. Available: http://www.worldbank.org/eca/russian/ (Accessed: 14.04.2015)

2. (2015) Sayt Mezhdunarodnogo Valyutnogo Fonda. Available: http://www.imf.org/external/russian/index.htm (Accessed: 14.04.2015).

3. Odintsov A (2011) Teoriya delovogo tsikla: kreditnyy «bum», pereproizvodstvo i dolgovoy krizis. Sayt «Oko planety», 01.08.11. Available: http://oko-planet.su (Accessed: 14.04.2015).

4. Glaz'ev S (2012) Krizis i okno vozmozhnostey// Informatsionno-analiticheskiy sayt «Oko planety», 03.09.12. Available: http://oko-planet.su/ (Accessed: 14.04.2015).

5. Grigor'ev O, Khazin M (2010) Problema riskov v sovremennoy ekonomike. Doklad na ekonomicheskom Forume v Astane (Kazakhstan) iyul' 2010 goda, Odnako, N 28 (44) 2010. - pp. 14-23.

6. Coghlan A, MacKenzie D (2011) Revealed the capitalist network that runs the world // Sayt «New scientist», 19.10.11. Available: http://www.newscientist.com (Accessed: 14.04.2015).

7. Perkins D (2008) Taynaya istoriya amerikanskoy imperii. Ekonomicheskie ubiytsy i pravda o global'noy korruptsii - M.: Al'pina Biznes Buks, 2008.- 448 p.

8. Krugman P (2007) The Conscience of a Liberal New York : W.W. Norton \& Co., 296 p.

9. Brzezinski Z (2012) Strategic Vision: America and the Crisis of Global Power. New York: Basic Books, 224 p.

10. Gav S (2011) Krizis kapitalizma? Net, krizis gosudarstv! Sayt RGRK «Golos Rossii», 16.09.11. Available: http://rus.ruvr.ru (Accessed: 14.04.2015).

11. Nazarbaev NA (2009) Pyatyy put' // Sayt gazety «Izvestiya», 22.09.09. Available: www.izvestia.ru (Accessed: 14.04.2015).

12. Khadson M (2011) Kak bednost' i strogaya ekonomiya vredyat ekonomicheskim interesam Rossii. Sayt «Chastnyy korrespondent», 18.09.11. Available: http://www.chaskor.ru (Accessed: 14.04.2015).

13. (2015) Sayt Agentstva RK po statistike. Available: $\quad$ www.stat.kz (Accessed: 14.04.2015).

14. (2011) Obzor «Investitsionnaya privlekatel'nost' Kazakhstana» (pravoobladatel' - kompaniya «Ernst end Yang») Mezhdunarodnyy delovoy zhurnal Kazakhstan №2, 2011. -pp. 12-17. 
15. (2015) Sayt AO «Tsentr razvitiya torgovoy politiki». Available: http://www.trade.gov.kz (Accessed: 14.04.2015).

16. (2015) Sayt Ministerstva industrii i novykh tekhnologiy Respubliki Kazakhstan. Available: www.mint.gov.kz (Accessed: 14.04.2015).

17. Rakhmatulina G, Isabekova K (2011) Vliyanie Tamozhennogo soyuza na razvitie malogo $\mathrm{i}$ srednego biznesa v Kazakhstane - Almaty: Agenstvo po issledovaniyu rentabel'nosti investitsiy, 2011. - 20 p.

18. (2015) Doklad po rezul'tatam kompleksnogo monitoringovogo issledovaniya sostoyaniya $\mathrm{i}$ problem malogo i srednego biznesa $\mathrm{v}$ Kazakhstane // Sayt Tsentra biznes-informatsii, sotsiologicheskikh i marketingovykh issledovaniy BISAM Central Asia. Available: http://www.bisam.kz/research/reports/msb.html (Accessed: 14.04.2015).

19. Gurevich L (2015) Kazakhstanskiy predprinimatel': samootsenka sobstvennoy istorii, prednaznacheniya i perspektiv// Sayt Tsentra biznes-informatsii, sotsiologicheskikh i marketingovykh issledovaniy BISAM Central Asia. Available: http://www.bisam.kz/research/reports/msb.html (Accessed: 14.04.2015).

20. (2014) Issledovatel'skiy proekt «Malyy i sredniy biznes Kazakhstana: sovremennaya situatsiya i perspektivnye napravleniya rosta». Otchet po rezul'tatam kompleksnogo sotsiologicheskogo issledovaniya - Almaty, 2014. - 45 p. Available: http://profinance.kz/2014/02/23/ (Accessed: 14.04.2015).

21. (2015) Issledovanie agentstva Reyting.kz «Ranzhirovanie regionov Respubliki Kazakhstan po kompleksu pokazateley». Available: http://i-news.kz/news/2012/05/28/ 6433675.html (Accessed: 14.04.2015).

22. Nazarbaev NA (2014) Poslanie Prezidenta RK narodu Kazakhstana. Astana, 2014. Available: http://www.akorda.kz (Accessed: 14.04.2015).

23. (2011) Sayt «Global'nyy monitoring predprinimatel'stva» (The Global Entrepreneurship Monitor), 2011. Available: http://www.gemconsortium.org (Accessed: 14.04.2015).

24. Kazhyken MZ (2015) Struktura ekonomiki Kazakhstana: osnovnye kharakteristiki disproportsiy i ikh prichiny. Available: www.kea-economics.kz (Accessed: 14.04.2015).

25. Zholdubekova G (2011) «Strane nuzhna novaya promyshlennaya politika» - Interv'yu s prezidentom Kazakhstanskogo instituta razvitiya industrii M.Kazhyken. Biznes i Vlast' №20 ot 10.06.11.

26. (2012) Sayt profinance.kz 17.05.12. Available: http://finance.nur.kz/ (Accessed: 14.04.2015).

27. (2010) Programma forsirovannogo industrial'no-innovatsionnogo razvitiya. Prinyata pravitel'stvom RK ot 23.02.10. // Ofitsial'nyy sayt Pravitel'stva Respubliki Kazakhstan. Available: http://ru.government.kz/documents/govprog (Accessed: 14.04.2015).

28. (2010) Postanovlenie Pravitel'stva Respubliki Kazakhstan №303 ot 14.04.10. O Karte industrializatsii Kazakhstana na 2010-2014 gody // Ofitsial'nyy sayt Pravitel'stva Respubliki Kazakhstan. Available: http://ru.government.kz/documents/govprog (Accessed: 14.04.2015).

29. (2015) Sayt AO «Kazakhstanskiy institut razvitiya industrii». Available: http://www.kidi.kz (Accessed: 14.04.2015).

30. (2010) Kontseptsiya razvitiya finansovogo sektora Respubliki Kazakhstan v postkrizisnyy period (utverzhdena Ukazom Prezidenta Respubliki Kazakhstan ot 01.02.10, № 923) Ofitsial'nyy sayt Prezidenta RK. Available: www.akorda.kz (Accessed: 14.04.2015).

31. (2011) Zakon RK «O vnesenii izmeneniy i dopolneniy $\mathrm{v}$ nekotorye zakonodatel'nye akty Respubliki Kazakhstan po voprosam regulirovaniya bankovskoy deyatel'nosti i finansovykh organizatsiy $\mathrm{v}$ chasti minimizatsii riskov Astana, 28.12.11g. № 524-IV ZRK // IS Paragraf, Available: www.zakon.kz (Accessed: 14.04.2015).

32. (2012) Programma «Proizvoditel'nost' 2020». Utverzhdena postanovleniem Pravitel'stva Respubliki Kazakhstan ot 14.03.11g., № 254 // IS Paragraf, 2012. Available: http://online.zakon.kz (Accessed: 14.04.2015).

33. (2015) Natsional'nyy investitsionnyy interaktivnyy veb-sayt. Available: http://www.invest.gov.kz (Accessed: 14.04.2015).

34. (2012) Sayt Kazakhstanskogo tsentra gosudarstvenno-chastnogo partnerstva, 09.05.12. Available: http://kzppp.kz (Accessed: 14.04.2015).

35. (2015) Sayt Programmy «Narodnoe IPO». Available: $\quad$ http://www.halyk-ipo.kz/ru (Accessed: 14.04.2015).

36. (2014) Nazarbaev N.A. Vystuplenie Prezidenta Kazakhstana pered studentami Nazarbaev Universiteta 2014 // Ofitsial'nyy sayt Prezidenta RK. Available: http://www.akorda.kz (Accessed: 14.04.2015). 